\title{
Reconsidering the arm span-height relationship in patients referred for spirometry
}

\author{
A. Capderou*,\# , M. Berkani", M-H. Becquemin ${ }^{\#, 9}$ and M. Zelter $\#$,
}

ABSTRACT: The interpretation of pulmonary function tests relies on reference values corrected for age, sex and height. Height may be difficult to measure in patients with deformities of the thoracic cage or those unable to stand up properly. Current practice is to substitute arm span to height, once corrected either by a fixed factor or by an age- and sex-dependent regression equation. However arm span may be difficult to measure in some patients.

This study evaluated the relationship between arm span, measured height, height as mentioned on an identity document (ID), sex and age in a population of 2,452 Caucasian subjects with no chest or spine deformities.

The present study demonstrates that age and sex have to be taken into account to best predict height from arm span or ID height values. The equations predicting height from ID height give the best diagnosis concordance compared to reference in males and females. Age correction does not improve concordance below 70 yrs.

The estimation of height from ID height can be substituted to that from arm span when clinically relevant, providing ID height has been measured before the occurrence of stature problems.

\section{KEYWORDS: Aging, arm span, body height, lower limit of normal, spirometry}

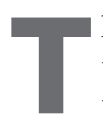
he interpretation of pulmonary function tests requires, as recommended by international societies, comparison of individual data to appropriate reference values, and more specifically to the lower limit of normal (LLN) [1]. These reference values are essentially dependent on age, sex and height. Detailed statements are available on how height should be measured [2]. For those patients with a deformity of the thoracic cage or who cannot stand up properly, substitution of measurement of arm span [3, 4], or knee height [5], when arm span cannot be measured, to height have been advocated, since quantitative relationships between them have been established. The use of a fixed ratio value of 1.06 between arm span and height has been suggested as allowing reasonable estimation of standing height from arm span, except at the extremes [2]. However, data obtained from North American $[6,7]$ and Indian populations [8] have clearly suggested that the ratio varies with age, ethnicity and sex, and that a single ratio may not be adequate for all. Therefore, regression equations between height and arm span in function of age and sex need to be obtained $[6,7,9]$. Overall, the fixed ratio may lead to misdiagnosis in variable proportions of patients [8].
Direct measurement of arm span may prove difficult or painful to perform in patients with spine diseases. Some patients may also experience difficulties correctly stretching their arms. Furthermore, the measurement takes time to be performed correctly, especially when the patient cannot stand upright. Because identity documents in many countries mention height at the time the documents were issued, this height value may provide, with or without correction for age, a simplified alternative to arm span measurement.

The aim of this study was to compare estimations of height from arm span (AS) and from the height mentioned on an identity document (H-ID) to measured height $(\mathrm{H})$, to assess whether these estimates need to be corrected for age and if the interpretation of pulmonary function tests may differ if height estimates are substituted to measured height. For this purpose, the measured height of a large series of patients with no anatomical or clinical suspicion of posture diseases was compared to estimated heights obtained by three methods: 1 ) a fixed ratio of the measured arm span, 2) a regression equation between arm span and measured height and 3) a regression equation

\section{AFFILIATIONS}

*Université Paris-Sud Faculté de Médecine Paris-Sud, Centre Chirurgical Marie Lannelongue, Service Physiologie, Le Plessis Robinson,

\#ER10-UPMC Université Paris, and •Assistance Publique, Hôpitaux de Paris, Groupe Hospitalier PitiéSalpêtrière, Service Central d'explorations Fonctionnelles Respiratoires, Paris, France.

CORRESPONDENCE

A. Capderou

Centre Chirurgical

Marie-Lannelongue Physiologie

133 avenue de la Résistance 92350 Le Plessis Robinson France

E-mail: andre.capderou@u-psud.fr

Received:

Dec 172009

Accepted after revision: May 192010

First published online:

June 072010 
between the height mentioned on an identity card or a passport. The effect of incorporating age as a factor in the regression equations was tested. The influence that the type of height correction might have on evaluating pulmonary function (forced expiratory volume in $1 \mathrm{~s}$ (FEV1), forced vital capacity (FVC) and total lung capacity (TLC)) was assessed by comparing LLN, calculated from the measured height and from the different estimated heights.

\section{METHODS}

\section{Subjects}

The study was performed on Caucasian patients, 20-90 yrs of age, referred to the hospital clinics for a suspected pulmonary disease over a period of 30 months. The local ethical committee approved the protocol. The only extra manoeuvre that was requested from the patients for the purpose of the study was the measurement of arm span, for which they were asked to give consent. No spirometry was performed specifically for this protocol. We excluded by physical examination and using medical records all patients suffering from abnormal spine curvature (scoliosis), whether classified as congenital, idiopathic or acquired, or secondary to another condition, such as cerebral palsy, spinal muscular atrophy or physical trauma, or major osteoporosis. Patients that could not stand erect properly for height measurement or stretch their arms for arm span measurements were also excluded.

A total of 2,452 patients (1,132 females and 1,320 males) were found to be eligible for the study, of which 2,372 (1,091 females and 1,281 males) were 20-80 yrs of age. Among these patients 2,353 (1,083 females, 1,270 males) held a government identity card (ID) on which H-ID was recorded at the time of issue. These patients were included in the various regression analyses, whether or not a spirometry was deemed necessary by the clinicians. Among the patients that actually had spirometry performed, 1,503 (701 females and 802 males) were within the age (18-70 yrs) and height range required to use the combined reference equations published in the 1993 European Respiratory Society (ERS) statement for lower limit of normal for FEV1, FVC, FEV1/FVC and TLC [10]. Obstruction was defined as FEV1/FVC below LLN and restriction as TLC below LLN. According to these criteria, 295 (19.6\%) patients were obstructive and $173(11.5 \%)$ restrictive.

\section{Data acquisition}

$\mathrm{H}$ and AS were measured according to American Thoracic Society (ATS)/ERS standards: $H$ was measured with a stadiometer, with shoes off and the patient standing erect with the head in the Frankfort horizontal plane [1]. H-ID was recorded. In the study population, it corresponded to the height of the subject actually measured by administrative authorities in the 18-30-yr age interval. AS was measured with the subject standing against a wall with the arms stretched to attain the maximal distance between the tips of the middle fingers. Measurement was done using a horizontal stadiometer placed on the plane wall surface behind the patient to avoid distortion due to body shape and to insure that fingertips were at the same horizontal level [9]. All spirometric and plethysmographic measurements were obtained by qualified technicians (Autobox plethysmograph, model 6200 Sensormedics; Yorba Linda, CA, USA) and satisfied ATS/ERS criteria [10].

\section{Statistical analysis}

Sets of regression equations were calculated for patients 2090 yrs of age between AS, H-ID and $\mathrm{H}$ with or without considering age as a significant factor, for each sex. As in all other studies, we made the implicit assumption that arm span does not vary with ageing in a given individual, apart from specific acquired deformities or diseases that disqualified patients from the study. We compared regression equations for males and females by slope and intercept analysis. We then compared height estimated from a fixed AS/ $\mathrm{H}$ ratio (using a fixed ratio), height estimated from AS and height estimated from $\mathrm{H}$-ID before and after correction for age, and $\mathrm{H}$ by repeated ANOVA and post hoc analysis, regrouping patients in 5 -yr age intervals. In order to assess the influence on diagnosis of residual errors committed when estimated heights were substituted to actually measured height in the LLN reference equations, we compared LLN corresponding to each height estimation to the reference LLN value [10] by ANOVA for repeated data and post hoc analysis, for each of the 5-yr age intervals. The analysis was performed for TLC, FEV1 and FVC but only on patients $20-70$ yrs of age, due to the age limits imposed by the reference equations. Finally, we tested the significance of changes in diagnosis resulting from the substitution of estimated heights to measured height in the LLN equations by calculating sensitivity, specificity, accuracy, positive and negative predictive values, and $\kappa$ test. Statistical analysis was performed with SPSS v16 software package (SPSS Inc., Chicago, IL, USA).

\section{RESULTS}

The fixed ratio of $\mathrm{AS} / \mathrm{H}$ in our population was 1.02 for males versus 1.01 for females (fig. $1 \mathrm{a}$ and $\mathrm{b}$ ). These values were statistically different $(\mathrm{p}<0.0001)$ and both were different from the unisex 1.06 value mentioned by MiLLER et al. [2] $(\mathrm{p}<0.0001)$. AS/H was found to vary significantly with age and sex by ANOVA $(p<0.001)$. Similarly, the H-ID/H ratio was calculated as a function of age and sex, and found to vary significantly as a function of both $(\mathrm{p}<0.001)$.

\section{Regression analysis as a function of age}

Regression equations between $\mathrm{H}$ and AS or H-ID are given in table 1 . They have been calculated with and without using age as a factor in the analysis. Slopes and intercepts of equations were significantly different between males and females $(p<0.01)$ whether or not age was considered a factor in the analysis, except slopes for H-ID when age was not incorporated.

The heights estimated for all patients from AS and H-ID equations were compared to $\mathrm{H}$ before and after taking age into account by a one-way repeated ANOVA, in which the analysis factor was the 5-yr age interval. When age was not taken into account, estimation of height from AS and H-ID did not differ significantly, but both differed significantly from $H(p<0.001)$ (fig. 2a and b). When age was taken into account, there was no significant difference between the estimates, or between estimates and $\mathrm{H}$, within any given age interval or between intervals, whether in males or in females (fig. $2 c$ and d). In this case, the only difference that could be found between methods was that the residual variance of heights estimated from H-ID was significantly lower than that of heights estimated from AS $(\mathrm{p}<0.001)$ (fig. 1c, d, e and f). 

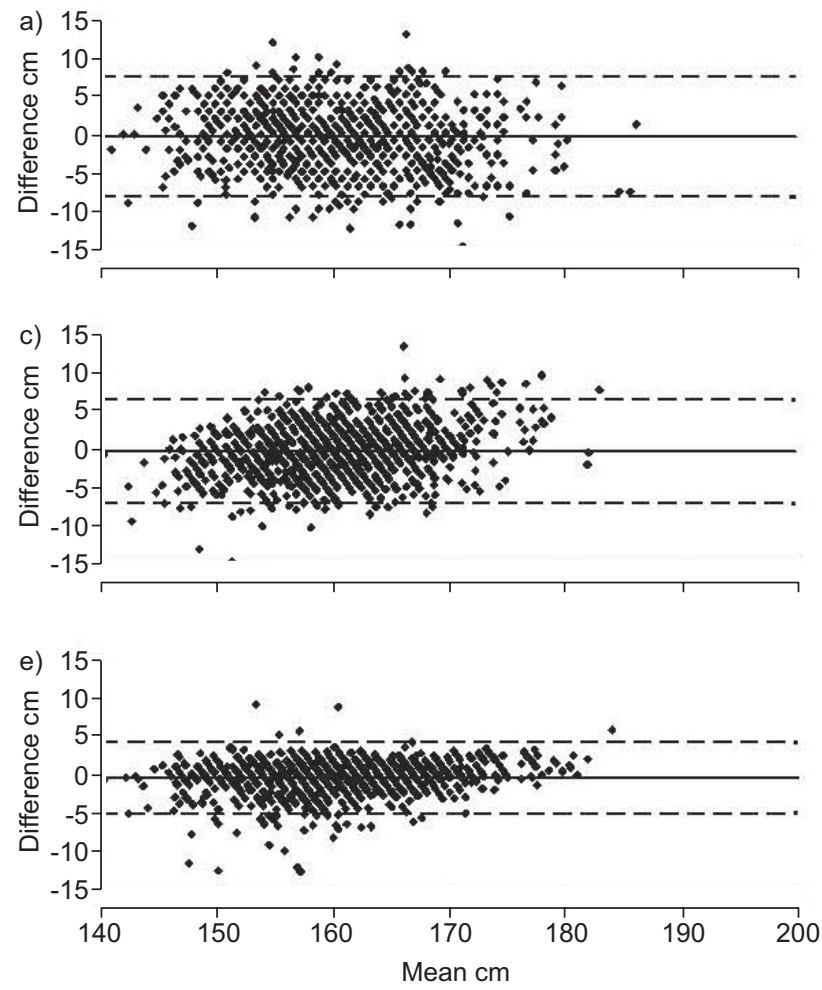

b)

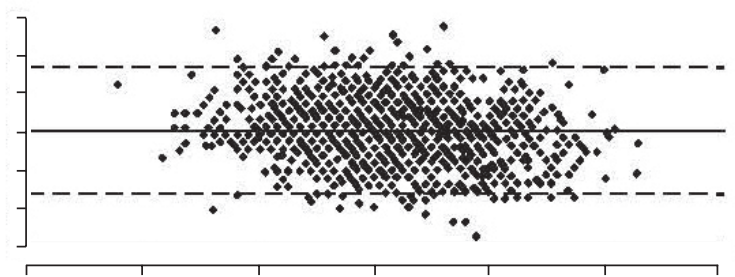

d)

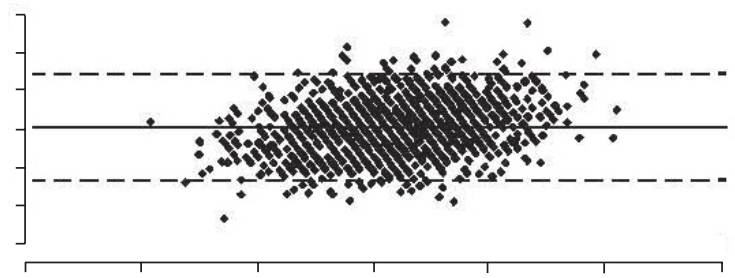

f)

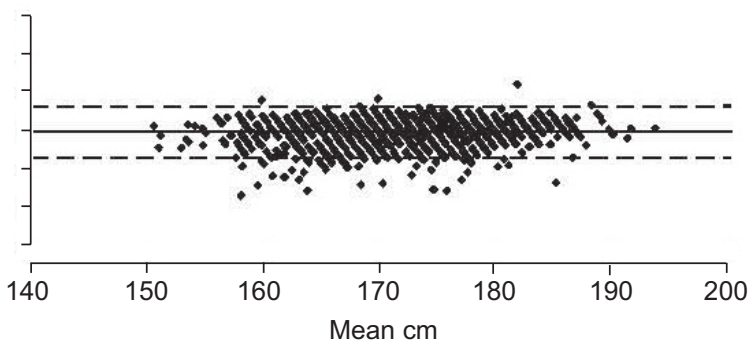

FIGURE 1. Bland-Altman comparisons a, b) between measured height $(H)$ and height estimated from arm span (AS) to height fixed ratio calculated from our population data for each sex ( 1.01 for females ( $a, c, e)$ and 1.02 for males $(b, d, f)$ ), c, d) between $\mathrm{H}$ and height estimated from AS regression equation with correction for age and e, f) between measured height and height estimated from the identity document height $(H-I D)$ regression equation with correction for age. —: bias; bias confidence limits $( \pm 2$ SEM) are not represented on the diagrams because of their very small magnitudes. ---: limits of agreement $( \pm 2 \mathrm{SD})$. Estimated heights calculated from AS and H-ID regression equations, taking age into account, show good correction of bias. Variance for estimation from H-ID is significantly lower than for estimation from arm span ( $<<0.001)$.

\section{Effect of height estimations on LLN values and diagnosis}

To assess quantitatively the impact of using estimates instead of $\mathrm{H}$ on LLN, we compared the values of LLN obtained from the reference equation for each estimate to the LLN obtained for $\mathrm{H}$ by repeated ANOVA in which the analysis factor was the 5 -yr age interval. When age was not taken into account, the LLN values for FEV1, FVC, TLC obtained from AS and H-ID estimates were not statistically different but differed from the LLN for $\mathrm{H}(\mathrm{p}<0.001)$. When age was taken into account, there was no significant difference. The qualitative impact on the diagnosis of substituting estimated heights to $\mathrm{H}$ in FEV1, FVC and TLC LLN equations is shown in table 2 for the 1,503 patients to which the equations were applicable. The distribution of mismatches is given in table 3 . The highest mismatch occurrence for any single measurement was for TLC, whether using height estimated from AS $(n=65)$ or height estimated from H-ID $(n=20)$.

Without correcting for age, classifications were fully concordant for FEV1, FVC and TLC in 1,396 patients (93\%, 95\% CI 91-94) using height estimated from AS versus 1,479 (98\%, 95\% CI 98-99) when using height estimated from H-ID.

After correction for age, classifications were fully concordant for 1,404 patients $(93 \%, 95 \%$ CI 92-95) using height estimated from AS versus 1,474 (98\%, 95\% CI 97-99) when using height estimated from H-ID. The concordance was significantly better for H-ID and H-ID corrected for age, compared to AS and AS after correction $(\mathrm{p}<0.05)$.

\section{DISCUSSION}

The fixed ratio values of $\mathrm{AS} / \mathrm{H}$ calculated for males and females were different but were within the range (1.01-1.04 for males and 1.00-1.02 for females) generally reported [3, 4], although ethnicity and population differed greatly between studies. All reported ratios, including ours, differed from the 1.06 value suggested by MiLLer et al. [2]. The present study confirmed that $\mathrm{AS} / \mathrm{H}$ is not fixed but is height- and agedependent; thus, the use of a fixed ratio may introduce a further level of uncertainty with regards to the predicted values of the lung function index, and may potentially lead to misclassification of disease $[2,8]$.

\section{Effects of correcting for age}

All available regression equations take sex and height as significant factors but this is not the case for age (table 1). Age was a significant factor in Caucasian males and females for LINDERHOLM et al. [9]. It was a significant factor for males only for Caucasians or Afro-Americans for PARKER et al. [6]. Regression equations differed noticeably not only with ethnicity but also between populations of the same ethnicity as shown when comparing data obtained by PARKER et al. [6], LiNDERHOLM et al. [9] and in this study on Caucasian subjects 


\begin{tabular}{|c|c|c|c|c|c|c|c|c|c|c|}
\hline \multirow{2}{*}{ TABLE 1} & \multirow[t]{2}{*}{ Eth. } & \multirow[t]{2}{*}{ Age yrs } & \multirow[t]{2}{*}{ Sex } & \multirow[t]{2}{*}{ Subjects $n$} & \multicolumn{3}{|c|}{ Without $A$ as a factor } & \multicolumn{3}{|l|}{ With $A$ as a factor } \\
\hline & & & & & Equation & SEE & $r^{2}$ & Equation & SEE & $r^{2}$ \\
\hline \multicolumn{11}{|c|}{ Between $\mathrm{H}$ and AS } \\
\hline Present study & & & M & 1281 & $H=43.0+0.73 \times A S$ & 3.8 & 0.69 & $H=54.1+0.70 \times A S-0.08 \times A$ & 3.6 & 0.72 \\
\hline \multirow[t]{2}{*}{ LINDERHOLM [9] } & C & $5-78$ & $\mathrm{~F}$ & 118 & & & & $H=9.9+0.94 \times A S-0.09 \times A$ & 3.6 & 0.94 \\
\hline & & & M & 91 & & & & $H=8.6+0.93 \times A S-0.07 \times A$ & 3.5 & 0.96 \\
\hline \multirow[t]{2}{*}{ PARKER [6] } & C & 20-89 & $\mathrm{F}$ & 70 & $\mathrm{H}=33.2+0.80 \times \mathrm{AS}$ & 3.4 & 0.77 & & & \\
\hline & & & M & 79 & & & & $H=68.7+0.63 \times A S-0.10 \times A$ & 4.1 & 0.72 \\
\hline ReEVES [7] & C & $23.3 \pm 5.5$ & $\mathrm{~F}$ & 116 & $H=34.3+0.80 \times A S$ & 3.2 & 0.71 & & & \\
\hline ReEves [7] & & & M & 50 & $H=54.9+0.66 \times A S$ & 3.5 & 0.79 & & & \\
\hline \multirow[t]{2}{*}{ ReEVES [7] } & 0 & $23.3 \pm 5.5$ & $\mathrm{~F}$ & 71 & $H=47.2+0.70 \times A S$ & 3.4 & 0.53 & & & \\
\hline & & & M & 69 & $H=42.7+0.74 \times A S$ & 3.4 & 0.72 & & & \\
\hline \multirow[t]{2}{*}{ ReEves [7] } & A & $23.3 \pm 5.5$ & $\mathrm{~F}$ & 44 & $H=81.0+0.48 \times A S$ & 3.3 & 0.56 & & & \\
\hline & & & M & 60 & $H=53.4+0.67 \times A S$ & 3.6 & 0.71 & & & \\
\hline \multicolumn{11}{|c|}{ Between $\mathrm{H}$ and $\mathrm{H}-\mathrm{ID}$} \\
\hline \multirow[t]{2}{*}{ Present study } & C & 20-79 & $\mathrm{F}$ & 1091 & $H=-0.7+0.99 \times H-I D$ & 2.4 & 0.88 & $H=9.2+0.96 \times H-I D-0.08 \times A$ & 2.1 & 0.91 \\
\hline & & & M & 1281 & $H=-1.7+1.00 \times H-I D$ & 1.8 & 0.93 & $H=7.1+0.97 \times H-I D-0.06 \times A$ & 1.6 & 0.94 \\
\hline
\end{tabular}

Data are presented as range or mean $\pm \mathrm{SD}$, unless otherwise stated. No regression without age available from LINDERHOLM et al. [9] as age is considered significant. No regression without age for males and with age for females available from PARKER et al. [6], as age is considered significant in males only. No regression equations with age available from REEVES et al. [7] because of the limited age range of subjects. A: age (in yrs); Eth.: ethnicity; SEE: standard error of the estimate (residual sD); $\mathrm{r}^{2}$ : coefficient of determination; C: Caucasian; AA: Afro-American; AC: Afro-Caribbean; O: Oriental; A: Asian; F: female; M: male.
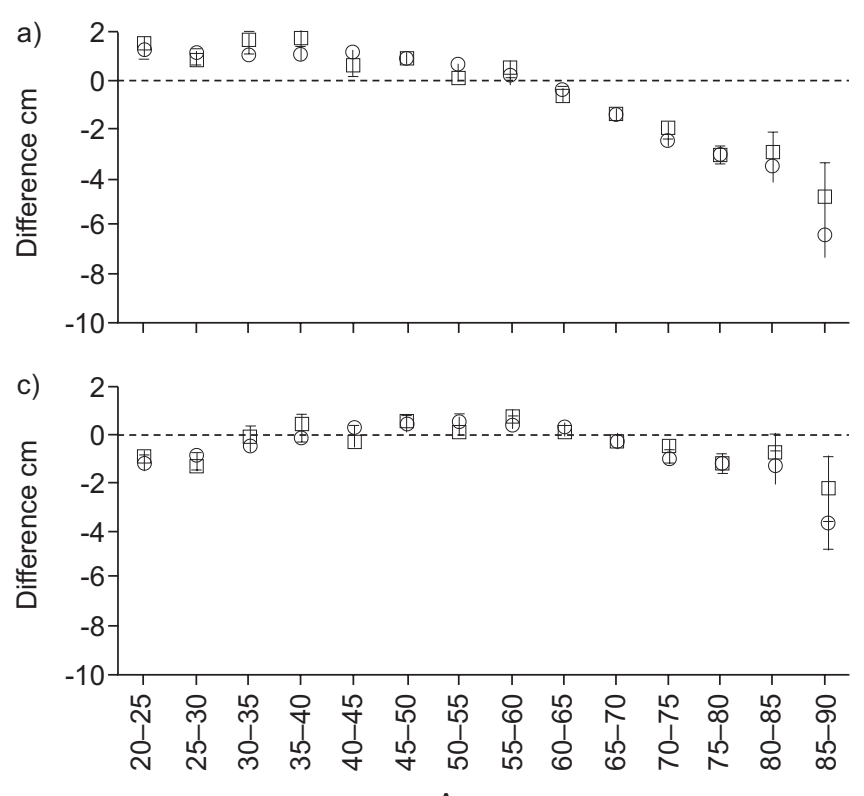

Age yrs b)

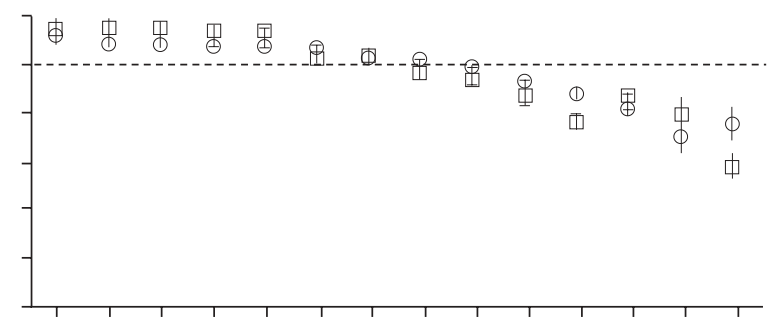

d)

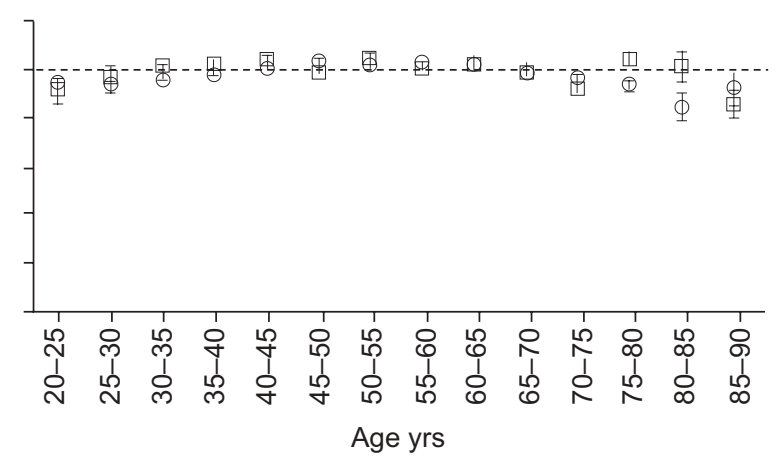

FIGURE 2. Difference between measured and estimated heights as a function of age $a$, b) before and $c, d)$ after correction for age in $a, c)$ females and b, d) males. Data are presented as mean \pm SEM. $\square$ : difference between measured height $(H)$ and height estimated from arm span; $O$ : difference between $\mathrm{H}$ and height estimated from identity document. 
TABLE 2 Effect of the height estimation method on diagnosis

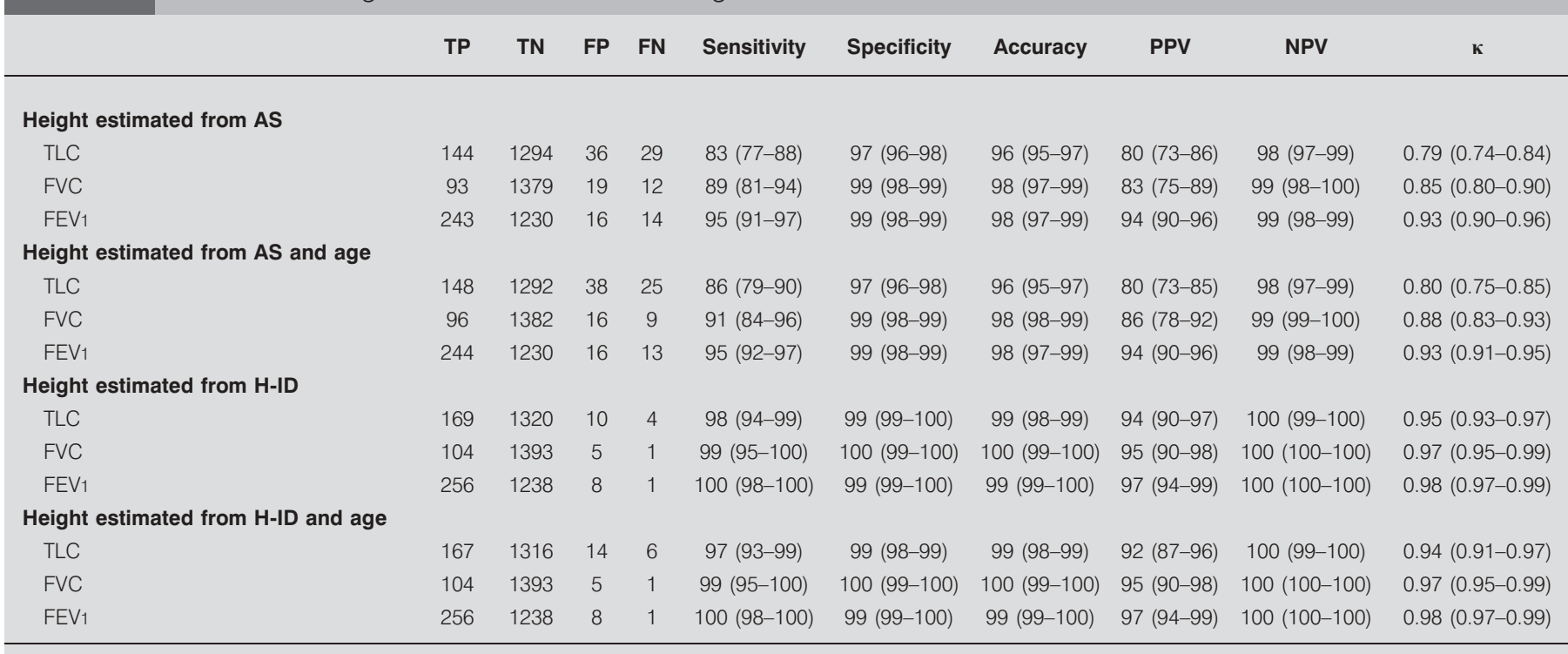

Data are presented as $\mathrm{n}$ or $\%(95 \% \mathrm{Cl})$, unless otherwise stated. Pooled data (males and females). Reference diagnosis based on lower limit of normal obtained with measured height. TP: true positive; TN: true negative; FP: false positive; FN: false negative; PPV: positive predictive value; NPV negative predictive value; AS: arm span TLC: total lung capacity; FVC: force vital capacity; FEV1: forced expiratory volume in $1 \mathrm{~s}$; H-ID: identity document height. ${ }^{*}: \mathrm{n}=1,503$.

(table 1). Interestingly, the regression equations of PARKER et al. [6] for Caucasians accounted for $72 \%$ of the variance in standing height in males and $77 \%$ in females versus 72 and $76 \%$ in the current study, respectively. The standard errors of the estimate of height were also quite similar: $4.1 \mathrm{~cm}$ for males and $3.4 \mathrm{~cm}$ for females in the study of PARKER et al. [6], versus $3.6 \mathrm{~cm}$ and $3.4 \mathrm{~cm}$ in the present study, although equations used differed. However, the variations observed between regression equations should be interpreted with some caution because of the limited number of subjects included in some of these studies $[6,9]$ compared to the present one, a factor that may explain some of the differences (table 1). Also, the inevitable cohort effect inherent on data obtained, in some cases, 30 yrs apart could not be accounted for, just as it can not be accounted for within any study, and might have biased comparisons.
Furthermore, no data are available on any eventual cohortrelated variation of AS relative to $\mathrm{H}$ during the same period of time, although such variation appears unlikely. In summary, this study confirms, in a large population, the need to establish population-specific regression equations that incorporate sex and age as significant factors.

\section{Effects of correcting for height}

In fact, $\mathrm{AS} / \mathrm{H}$ was not only dependent on age, but also partially on height, as previously suspected $[6,7,9]$. This was confirmed in this study by the fact that the regression equations, calculated separately for all 5-yr age interval groups had similar slopes but statistically different intercepts and that all intercepts were significantly different from zero $(p<0.001)$. Therefore, it can be speculated that the age factor in the arm

TABLE 3 Number and type of single and multiple diagnosis mismatches according to estimation method ${ }^{\#}$

\begin{tabular}{|c|c|c|c|c|c|c|c|c|c|}
\hline $\begin{array}{l}\text { Estimation } \\
\text { method }\end{array}$ & Matched & Mismatched & TLC & FVC & FEV $_{1}$ & TLC+FVC & TLC+FEV1 & FVC+FEV1 & TLC+FVC+FEV 1 \\
\hline AS+age & 1404 & 99 & 49 & 12 & 21 & 9 & 4 & 3 & 1 \\
\hline $\mathrm{FP}$ & & 58 & 27 & 7 & 12 & 8 & 3 & 1 & 0 \\
\hline FN & & 41 & 22 & 5 & 9 & 1 & 1 & 2 & 1 \\
\hline H-ID+age & 1474 & 29 & 17 & 2 & 6 & 1 & 0 & 1 & 2 \\
\hline FP & & 23 & 12 & 2 & 6 & 1 & 0 & 1 & 1 \\
\hline $\mathrm{FN}$ & & 6 & 5 & 0 & 0 & 0 & 0 & 0 & 1 \\
\hline
\end{tabular}

Data are presented as n. Pooled data (males and females). Total mismatched subdivided in false positives (FP) and false negatives (FN). Columns detail the distribution of the number of mismatches according to type of volume(s). Note the low number of patients with cumulated mismatches. TLC: total lung capacity; FVC: forced vital capacity; FEV1: forced expiratory volume in $1 \mathrm{~s}$; AS+age: regression equation between measured height $(\mathrm{H})$ and arm span taking age into account; $\mathrm{H}$-ID+age: regression equation between $\mathrm{H}$ and identity document height taking age into account. ${ }^{*}$ : $\mathrm{n}=1503$. 
span equations reflected the effect of age per se but also possibly, at least in part, a cohort effect.

This was not the case for the ratio of H-ID to $\mathrm{H}$, which was not dependent on height, as demonstrated by the fact that the slopes of the regression equations calculated for the 5-yr age interval groups were different but their intercepts were not and these intercepts were not significantly different from zero. This strongly suggested that the loss in height with age, calculated from H-ID, reflected only the effect of ageing and not a cohort effect. However, because the regression equations for H-ID and AS did not differ, an eventual cohort effect, indirectly shown by the different relationship to height, was not significant enough to influence the results.

\section{Limitations of estimation from $\mathrm{H}$-ID}

We hypothesised that H-ID was actually and correctly measured when the subject was a young adult. In fact, the potential limitation of this assumption did not appear significant, as the difference between $\mathrm{H}$ and $\mathrm{H}$-ID was $<2 \mathrm{~cm}$ up to $60 \mathrm{yrs}$ of age (fig. 2). A strong argument showing that the date of issue of the ID document did not interfere with estimated height value was given by the fact that the slopes and intercepts of the regression equations between H-ID and AS did not differ significantly between age intervals. Apart from its simplicity, evaluating height from H-ID led to the lowest number of misdiagnoses when compared to measured height (table 2). However, this remained a marginal finding, as the quantitative analysis of the LLN data by ANOVA showed no significant difference between incorporating $\mathrm{H}$, or height estimated from H-ID or AS in the LLN equations, providing age correction had been taken into consideration. Although correction for age was statistically highly significant for estimating height, qualitatively, it resulted in a very limited number of changes in diagnosis either for AS or H-ID. Concordance did not change statistically when AS or H-ID estimates were corrected for age but both the H-ID and H-ID corrected for age estimates led to significantly better concordance. The few discrepancies between H-ID and age-corrected H-ID estimates concerned only TLC. They were observed when the difference between $\mathrm{H}-\mathrm{ID}$ and $\mathrm{H}$ was $>5 \mathrm{~cm}$, suggesting transcription errors or poor H-ID measurements. Therefore, age correction might seem superfluous for diagnosis at $<70$ yrs of age. Above that age, the magnitude of the correction might become large enough (fig. 2) to induce significant changes of diagnosis, but this hypothesis could not be tested here due to the limits of the validity of the reference equations. In fact, the very limited number of patients for whom a change of diagnosis linked to the estimation method used (table 2) all had measured volume values within $300 \mathrm{~mL}$ of the LLN values, i.e. within 1.5 times the $200 \mathrm{~mL}$ precision limits expected for volume measurements.

\section{Knee height versus $A S$ and $H$-ID estimates}

The World Health Organization (WHO) has recommended that when stature cannot be measured, it should be predicted from a measure of knee height rather than AS, particularly in persons $\geqslant 60$ yrs of age, as AS may be less satisfactory than knee height because of joint stiffness in the elderly and because the number of joints involved can reduce the accuracy of measurement [11]. The use of knee height was not attempted in this study, as our purpose was to simplify the procedure to estimate height in disabled people whenever feasible; thus, we suggest using H-ID when appropriate. The procedure of knee height measurement undeniably necessitates time to position adequately the patient and extra expertise to position the sliding calliper correctly [5]. Furthermore, the standard errors derived from the equations developed for estimating height from knee height for North-American Caucasians [12], taking age into account, are rather large $(7.84 \mathrm{~cm}$ for males and $8.82 \mathrm{~cm}$ for females, respectively) compared to the standard errors for height derived from arm span given by PARKER et al. [6] in the same type of population $(4.12 \mathrm{~cm}$ and $3.39 \mathrm{~cm}$, respectively), by LINDERHOLM et al. [9] in a Swedish population $(3.51 \mathrm{~cm}$ and $3.60 \mathrm{~cm}$, respectively) and by the present study in a French Caucasian population $(3.60 \mathrm{~cm}$ and $3.42 \mathrm{~cm}$, respectively). However, knee height can almost always be obtained instead of AS or H-ID.

\section{Limits of H-ID estimates}

In the case of patients with congenital diseases, the theoretical height can only be estimated from AS or knee height, because $\mathrm{H}$ and $\mathrm{H}-\mathrm{ID}$ are irrelevant. The normal changes in lung function with age in these patients are not well known. Consequently, the interpretation of lung function data derived from any estimated height should be viewed with caution.

Concerning acquired skeletal diseases, H-ID can be used to estimate the height the patient would have had if deformities had not occurred, but only if H-ID has been obtained before the onset of the skeletal disease. If there is no certainty as to when $\mathrm{H}$-ID was obtained in relation to the disease, then AS or knee height should be used. In this case, as in all others, the estimated height will allow to calculation of the most relevant LLN, but that this will still not allow determination of what part of the changes are directly linked to the underlying disease rather than to acquired deformities. Finally, the point should be made that, at present, there are no guidelines regarding the degree of spinal curvature that would invalidate the direct measurement of height. Consequently, the choice of normal subjects incorporated to establish regression equations, as well as that of patients susceptible to benefit from such equations, remains observer-dependent. Its impact cannot be properly assessed but is probably very limited [11].

\section{Conclusion}

The height of a subject can be estimated with confidence from their AS or H-ID, providing appropriate regression equations corrected for age are available. Height estimated from H-ID gives more concordant diagnosis compared to reference values than height estimated from AS. Correction of H-ID for age does not improve concordance, at least in patients $\leqslant 70 \mathrm{yrs}$ of age. H-ID offers a simple alternative to AS measurement, with the limitation that it should be measured acturately before significant stature impairment occurred.

\section{STATEMENT OF INTEREST}

None declared.

\section{REFERENCES}

1 Pellegrino R, Viegi G, Brusasco V, et al. Interpretative strategies for lung function tests. Eur Respir J 2005; 26: 948-968. 
2 Miller MR, Crapo R, Hankinson J, et al. General considerations for lung function testing. Eur Respir J 2005; 26: 153-161.

3 Bardeen CR. The height-weight index of build in relation to linear and volumetric proportions and surface area of the body during post-natal development. Contributions to Embryology 1920; 9: 485-554.

4 Hepper NGG, Black LF, Fowler WS. Relationships of lung volume to height and arm span in normal subjects and in patients with spinal deformity. Am Rev Respir Dis 1965; 91: 356-362.

5 Chumlea WC, Guo SS, Wholihan K, et al. Stature prediction equations for elderly non-Hispanic white, non-Hispanic black, and Mexican-American persons developed from NHANES III data. J Am Diet Assoc 1998; 98: 137-142.

6 Parker JM, Dillard TA, Phillips YY. Arm span-height relationships in patients referred for spirometry. Am J Respir Crit Care Med 1996; 154: 533-536.
7 Reeves SL, Varakmin C, Henry CJ. The relationship between armspan measurement and height with special reference to gender and ethnicity. Eur J Clin Nutr 1996; 50: 398-400.

8 Aggarwal AN, Gupta D, Jindal SK. Interpreting spirometric data: impact of substitution of arm span for standing height in adults from North India. Chest 1999; 116: 1837-1838.

9 Linderholm H, Lindgren U. Prediction of spirometric values in patients with scoliosis. Acta Orthop Scand 1970; 49: 469-474.

10 Miller MR, Hankinson J, Brusasco V, et al. Standardisation of spirometry. Eur Respir J 2005; 26: 319-338.

11 World Health Organization. Physical Status: The use and Interpretation of Anthropometry. Report of a WHO Expert Committee. Geneva, World Health Organization, 1995.

12 Chumlea WC, Guo S. Equations for predicting stature in white and black elderly individuals. J Gerontol 1992; 47: M197-M203. 